\title{
The escape behaviour of wild Greek tortoises Testudo graeca with an emphasis on geometrical shape discrimination
}

\author{
Alexandra Glavaschi, Ellen S. Beaumont ${ }^{*}$ \\ Department of Biological and Forensic Sciences, University of Derby, Derby, UK. \\ * Correspondence: Department of Biological and Forensic Sciences, University of Derby, Kedleston Road, Derby, DE22 1GB, \\ UK. Phone: +44 (01332) 591156, E-mail:e.beaumont@derby.ac.uk
}

Received: 17 December 2013; received in revised form: 11 July 2014; accepted:14 July 2014.

Geometrical shape discrimination has been shown to play an important role in the spatial orientation of a wide variety of mammals and birds, while the study of this ability in particular and of cognitive processes in general has been rather neglected in reptiles. The present experiment aims to investigate the ability of wild Greek tortoises Testudo graeca from Topolog forest, Tulcea County, Romania, to discriminate between simple geometrical shapes. Forty-two adult tortoises were subjected to a task consisting of escaping from a square arena through one of the four available doors, each with a geometrical shape attached. Thirty-one individuals completed 10 consecutive trials, requiring significantly less time for the last trial than for the first. This trend suggests that Greek tortoises developed and used an escape strategy, most likely relying on the geometrical shapes provided as cues. This experiment is the first to explore the cognitive processes of this species and further work should expand on the ecological significance of this ability.

Key words: cognitive abilities; navigation; orientation; Romania; Tulcea; visual cues.

Conducta de fuga en tortugas moras Testudo graeca salvajes con énfasis en la discriminación de formas geométricas. Se ha visto que la discriminación de formas geométricas juega un papel importante en la orientación especial de una gran variedad de mamíferos y aves, pero el estudio en reptiles de esta capacidad en particular, y de los procesos cognitivos en general, ha recibido poca atención. El experimento que aquí se presenta tiene por objeto investigar la capacidad de tortugas moras Testudo graeca salvajes procedentes del bosque Topolog, distrito de Tulcea, Rumanía, de discriminar entre formas geométricas simples. Cuarenta y dos tortugas adultas fueron sometidas a una prueba para escapar de un espacio cuadrado mediante una de las cuatro puertas disponibles, cada una de las cuales tenía pegada una forma geométrica. Treinta y un individuos completaron tres intentos consecutivos, necesitando para el último intento un tiempo significativamente inferior que para el primero. Esta tendencia sugiere que las tortugas moras desarrollaron y utilizaron una estrategia de fuga, muy probablemente dependiente de las formas geométricas proporcionadas como señales. Este experimento es el primero en explorar el proceso cognitivo de esta especie, y el significado ecológico de esta capacidad deberá ser investigado en próximos estudios.

Key words: capacidades cognitivas; navegación; orientación; Rumanía; señales visuales; Tulcea.

Efficient navigation is of obvious importance in an animal's daily activities and relies on different orientation mechanisms that make use of a wide variety of cues, including the sun, moon, stars, polarized light, auditory, chemical, electrical and visual cues (ABLE, 1991). Two types of visual cues are recognized in studies of spatial orientation: geometrical cues (the overall shape of the environment, the distinction between left and right, angles and distances), and non-geometrical or featural cues (including colour, texture and brightness) (CHENG, 1986). 
As shown for species like rats (CHENG, 1986), human children (HERMER \& SPELKE, 1996), rhesus monkeys Macaca mulatta (GouteuX et al., 2001), red tails plitfins Xenotoca eiseni (SOVRANO et al., 2002, 2003), or Neotropical ants Gygantiops destructor (WystraCH \& BEUGNON, 2009), the overall geometry of the environment is used primarily in orientation tasks. The importance of global geometry for spatial orientation makes sense from an ecological point of view. In an animal's natural environment, the overall layout (shapes and distances between important landmarks) remains unchanged across seasons, whereas more local cues such as colours, textures, and brightness may change (for example, due to season change). Thus, the global geometry is more reliable for animal orientation (CHENG \& GALLISTEL, 1984; Gallistel, 1990; Hermer \& SpelKe, 1996).

However, smaller, more local cues cannot be ignored. The ability to use geometric properties of more specific objects, as opposed to the geometry of the environment discussed so far, must be adaptive, as it provides animals with vital information for everyday activity. Various species have been studied in terms of their perception of geometrical shapes and visual discrimination ability. Sand fiddler crabs (Uca pugilator) with no previous training that were presented simultaneously with stationary geometrical shapes of equal surface areas exhibited various response strengths, in descending order as follows: vertical rectangle $>$ horizontal rectangle $>$ triangle > square > circle (LANGDON \& HERRNKIND, 1985). Moreover, chemically stimulated heaping fiddler crabs (Uca cumulanta) navigated away from striped rectangles that resembled seagrass meadows inhabited by predators, and orientated towards vertical ovals perceived as refuge sites (CHIUSSI \& DiAZ, 2002). Similarly, some species of hermit crabs and mangrove crabs can learn to associate geometrical shapes with either shelters (represented by gastropod shells of various qualities) or predators, depending on the size and the angle at which the shape is positioned (OrIHUELA et al., 1992; DiAZ et al., 1994, 1995). Cotton-top tamarins (Saguinus oedipus) subjected to a foraging task in an artificial jungle were not affected by changes in the overall shape of the environment whereas alterations of the landmark shape resulted in significant performance disturbance (Deipolyi et al., 2001).

Geometrical shape discrimination is also reported in several species of fish, such as the African cichlid Pseudotropheus sp., which could distinguish between two-dimensional geometrical shapes of various sizes and differentiate between two categories of objects, "fish" and "snail" (SCHLUESSEL et al., 2012) and the Ambon damselfish, Pomacentrus amboinensis, which could rapidly learn to discriminate between bi-dimensional and tridimensional objects (SIEBECK et al., 2009). The experimental design ensured a gradual reduction of the number of stimuli until only overall shape remained, which was still enough for the fish to discriminate accurately (SiEbECK et al., 2009).

It has long been assumed that amphibians and reptiles are not capable of learning to an extent comparable to mammals and birds, mainly due to the lack of anatomical structures involved in advanced cognitive processes (SUBOSKI, 1992). However, the interest in reptile intelligence has a relatively long history (reviewed in Burghardt, 1977, cited in WILKINSON 
et al., 2007). Reptiles have been found to perform similarly to mammals and birds in spatial orientation tasks (LÓPEZ et al., 2000, 2001) and there is a growing body of evidence suggesting that the medial cortex of reptiles is equivalent to mammalian and avian hippocampus in terms of its role in spatial memory (RODRíGUEZ et al., 2002; LÓPEZ et al., 2003).

The most recent information concerning cognitive aspects of chelonians comes from the study of the red-footed tortoise, Chelonoidis carbonarius. The animals performed above chance in an eight-arm radial maze, never re-entering an arm they just exited from (WILKINSON et al., 2007) and, when available, using extra-maze cues to orient (WILKINSON et al., 2009). Although a solitary species, red-footed tortoises are able to learn to navigate by observing conspecifics (WILKINSON et al., 2010) and have the capacity to discriminate between real objects and pictures of them (WILKINSON et al., 2013).

The Greek tortoise, Testudo graeca, has been studied in terms of population structure and dynamics (LAMBERT, 1982; ZNARI et al., 2005), diet (EL Mouden et al., 2006) and other biological aspects, such as the influence of testosterone on male reproductive behaviour and space use (SEREAU et al., 2010), but there is a lack of literature concerning cognitive aspects of this species.

The present study focuses on the ability of the Greek tortoise to orient using proximal visual cues in order to escape from a square enclosure. It has been already confirmed for other chelonians that the visual system plays an important role in their daily activities (MäTHGER et al., 2007; NARAZAKI et al., 2013) and related spatial orientation abilities have been described for the red-footed tortoise
Chelonoidis carbonarius (WILKINSON et al., 2007, 2009, 2013). When provided with geometrical shapes attached to a curtain surrounding the test maze, the red-footed tortoise did not use them to navigate (WILKINSON et al., 2009). By designing a maze of appropriate complexity and testing a large enough sample to compensate for the limited control, this experiment aims to assess whether the ability to discriminate between simple geometrical shapes actually exists in tortoises and explores the hypothesis that the subjects will require gradually less time to complete a trial-and-error test involving escaping from a box with three "false" and one "true" exit.

\section{Materials AND Methods}

\section{Animals and area of study}

The Greek tortoise inhabits temperate and Mediterranean areas and is unevenly distributed in south-east Romania, following mixed deciduous forests (TORTOISE \& Freshwater Turtle Specialist Group, 1996; Covaciu-Marcov et al., 2006). The population found in Topolog forest in Tulcea County has never been surveyed, but sightings are frequently reported by locals (the forest is exploited for timber and the surroundings are used as pastures) between mid-March and late October (A. Glavaschi, personal observation). An area of approximately 10 ha in SE Romania (Tulcea county, $44^{\circ} 50^{\prime} \mathrm{N}, 28^{\circ} 25^{\prime} \mathrm{E}$ ) was surveyed in August 2012.A total of 42 adult specimens (32 males, 10 females) of unknown life histories and health conditions, though all experimentally naïve, were tested. The number of annuli and the overall carapace aspect were used to 
approximate age. Males and females were differentiated according to plastron characteristics: males showed wider openings around the legs, a concavity around the suture between the abdominal scutes, a convex supracaudal scute with the cavity above the tail and the tips of the anal scutes relatively wide apart, whereas in females the leg openings are narrower and the plastron is flat, as well as the supracaudal scute, and the distance between the tips of anal scutes being considerably smaller (LAMBERT, 1982; see CARRETERO et al., 2005, for a schematic representation of the tortoise carapace and plastron).

\section{The experimental device}

A $45 \times 45 \times 31 \mathrm{~cm}$ cardboard box (square base) was manufactured. The walls were of the same lengths to prevent tortoises from orientating by the shape of the environment, as described above. To reduce the differences to the geometrical shapes available for orientation, a $27 \mathrm{~cm}$ wide, $20 \mathrm{~cm}$ high door was cut through each wall at equal distances to the corners. Geometrical shapes of similar surface areas were attached on the inside of each door as follows, in a clockwise order when viewed from above: triangle, circle, rectangle and square (Fig. 1). All shapes were made from standard printing paper and painted solid black with watercolors. Paper glue was used for attachment. Because all geometrical shapes used as visual cues were regular and equally unlikely to be encountered in nature, the triangle was randomly selected to be attached to the "true" exit. The door could easily be pushed outwards so that the tortoises could escape. All the other doors were blocked on the outside with adhesive tape.

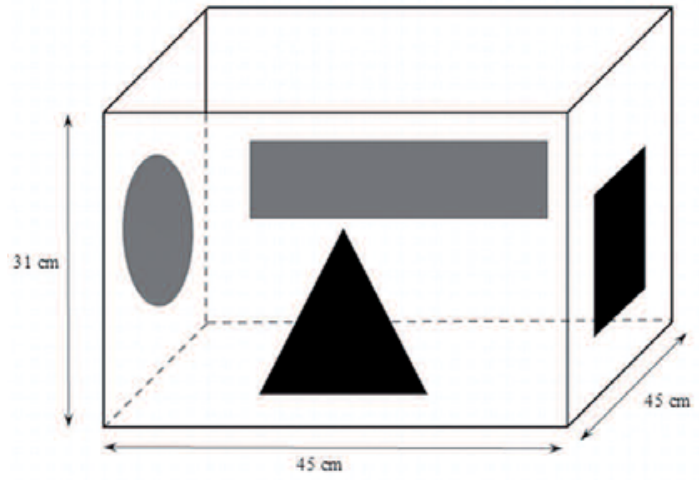

Figure 1: Schematic representation of the box showing dimensions and the position of each geometrical shape relative to the other three. Door edges not shown.

\section{Procedure}

Tortoises were encountered throughout the day, between 08:00 and 18:00. At the moment of encounter, the individuals were allowed to become familiar of being in close proximity to the experimenter for approximately 20 minutes during which time the experimental setup took place. The box was placed on the nearest flat, shaded area. In some cases, extraneous cues such as tree branches, plants, clouds and stones were visible from inside the box.

Tortoises were always placed in the centre of the box, facing the rectangle (with the correct exit directly behind them). A standard digital stopwatch was used to measure the time needed to locate and operate the correct door. Any other movements performed inside the box were timed and noted. Air temperature was measured using a digital thermometer. The animals were observed from a minimum distance of $1.5 \mathrm{~m}$ in order to minimize experimenter effects.

Once outside, each individual was allowed to walk approximately $5 \mathrm{~m}$ away from the box, while the box was set again for the next trial, 
then the animal was placed back inside the box in the same orientation as originally. A trial was considered completed when half of the animal was outside the box. A test consisted of ten consecutive trials for each individual. A fresh piece of apple was placed in front of the correct door as a food reward; however, on no occasion were the tortoises interested in it. Perfume-free wet wipes were used to wipe the walls and floor of the box after each individual had finished the test, to minimize any scent trials that might have influenced subsequent subjects.

The overall time needed to complete the trials, comprising the latency to the first movement and the active search time, were analyzed to determine any decrease that would indicate that learning has occurred.

A trial was considered failed if the animal could not find the exit after 15 minutes of moving around the box or was inactive for 10 minutes, in which case the door was fixed open and the animal allowed to escape. In some cases, the individuals had to be handled so that they faced the open door. An individual was allowed to fail three consecutive trials. If the fourth trial was also unsuccessful, the specimen was not subjected to further testing. The test was also abandoned if the subject showed clear signs of stress (such as urinating, defecating, gular pumping or retracting for more than five minutes) at any stage of the test. To avoid false replicas, tested individuals were marked on the plastron using blue nail polish. After marking, animals were released in the exact location and orientation they were encountered in. Handling was limited to placing individuals in the box after each completed trial, marking, photographing and, in a few cases, placing the animal facing the correct exit, and this was done with maximum caution.

\section{Statistics}

To assess whether the performance improved between the beginning and the end of the test, differences between the first and last trial were calculated for all variables: latency to the first movement, active search time and overall time. The data set was tested for normality and homogeneity of variance using Shapiro-Wilk tests and graphical methods (results not shown). According to these results, Wilcoxon signed-rank tests were used to compare between the times (median numbers of seconds) needed for the first, fifth and last trial, to explore the variation in performance. The results from the other trials were not used in statistical tests to avoid any potential errors. Spearman's correlations were conducted in order to assess whether the latency to the first movement, the active search time and the overall time varied independently from one another or whether there were any interactions.

Potential effects of the activity at the moment of encounter were examined. Individuals found walking, digging burrows or interacting with conspecifics were classified as being involved in a "high" level of activity, whereas tortoises found hidden under leaves, drinking, feeding or basking were included in the "low" level of activity category. Wilcoxon signed-rank tests were conducted to see whether search time was influenced by the activity at the moment of encounter.

To determine whether the subjects actually used the geometrical shapes as a guidance strategy as opposed to simply remembering what direction to follow, the percentage of times the first successful movement was repeated was calculated. Similarly to the method used by RoDrígueZ et al. (2002), 
the tortoises in the present experiment were considered to follow a certain pattern if $80 \%$ (8 out of 10) of the first movements were identical with each other and the first successful movement.

The temperature effects were examined by comparing the results of successful individuals below and above $30^{\circ} \mathrm{C}$ and by looking for significant differences between the temperatures experienced by successful and unsuccessful individuals. Again, the distribution was explored using Shapiro-Wilk tests and Wilcoxon signed-rank tests were used for the analyses.

The results were considered statistically significant at a $\mathrm{P}$ value of 0.05 . All calculations were performed using $\mathrm{R}$ statistics package (R Development Core Team, 2008).

\section{RESULTS}

Thirty-one of the 42 individuals tested were successful (25 males and six females), i.e. completed 10 trials with or without additional failed trials, and were used in statistical tests. Six of the successful individuals (five males and one female) failed between one and three trials.

The mean difference between the overall time needed to complete the first and last trial is well above $0(210 \pm 195 \mathrm{~s})$. The overall time spent inside the box decreased as the test progressed. Significant differences can be observed between the first and fifth trials (Wilcoxon signed-rank test: $\mathrm{W}=487, P<0.001$, $\mathrm{N}=31$; first trial: median time $=269 \pm 233 \mathrm{~s}$; fifth trial: median time $=96 \pm 106 \mathrm{~s}$ ) and also between the first and tenth trials ( $\mathrm{W}=456$, $P<0.001, \mathrm{~N}=31$; first trial: median time $=269$ $\pm 233 \mathrm{~s}$; tenth trial: median time $=94 \pm 155 \mathrm{~s}$ ). The performance remained constant during the second half of the test, as reflected by the lack of significant difference between the fifth and tenth trial $(\mathrm{W}=193, P=0.603, \mathrm{~N}=31$; fifth trial: median time $=96 \pm 106 \mathrm{~s}$; tenth trial: median time $=94 \pm 155 \mathrm{~s}$ ). As illustrated by the error bars in Fig. 2a, individual subjects exhibited different levels of activity. The main source of variation in the overall time is represented by its second component, the time used to actively explore the box. Similarly, this decreases significantly during the first part of the test ( $\mathrm{W}=480, P<0.001$, $\mathrm{N}=31$; first trial: median time $=220 \pm 235 \mathrm{~s}$; fifth trial: median time $=55 \pm 114 \mathrm{~s}$ ) and the performance is maintained until the end $(\mathrm{W}=470.5, P<0.001, \mathrm{~N}=31$; first trial: median time $=55 \pm 114 \mathrm{~s}$; tenth trial: median time $=45 \pm 150 \mathrm{~s}$ ), with no significant improvement between the fifth and tenth trial $(\mathrm{W}=188, P=0.530, \mathrm{~N}=31$; fifth trial: median time $=55 \pm 114 \mathrm{~s}$; tenth trial: median time $=45 \pm 150 \mathrm{~s}$ ) (Fig. 2b). Although not as obviously as the other variables, latency also decreases. At the beginning ofthe fifth trial, tortoises take less time to start exploring the box than in the first trial $(\mathrm{W}=288, P=0.004$, $\mathrm{N}=31$; first trial, median latency $=26 \pm 53.5 \mathrm{~s}$; fifth trial: median latency $=0 \pm 45.5 \mathrm{~s}$ ) and the performance remains the same until the tenth trial $(\mathrm{W}=110, P=0.603, \mathrm{~N}=31$; fifth trial: median latency $=0 \pm 45.5 \mathrm{~s}$; tenth trial: median latency $=10 \pm 35 \mathrm{~s}$ ) (Fig. 2c). As illustrated by the error bars in Figs. 2a-c, wide variation between individual performances was observed. When all the variables are plotted together (Fig. 2d) it is readily visible that the overall time and the active search time vary similarly whereas the latency remains constant.

This final point is further supported by the strong correlation reported by Spearman's test 

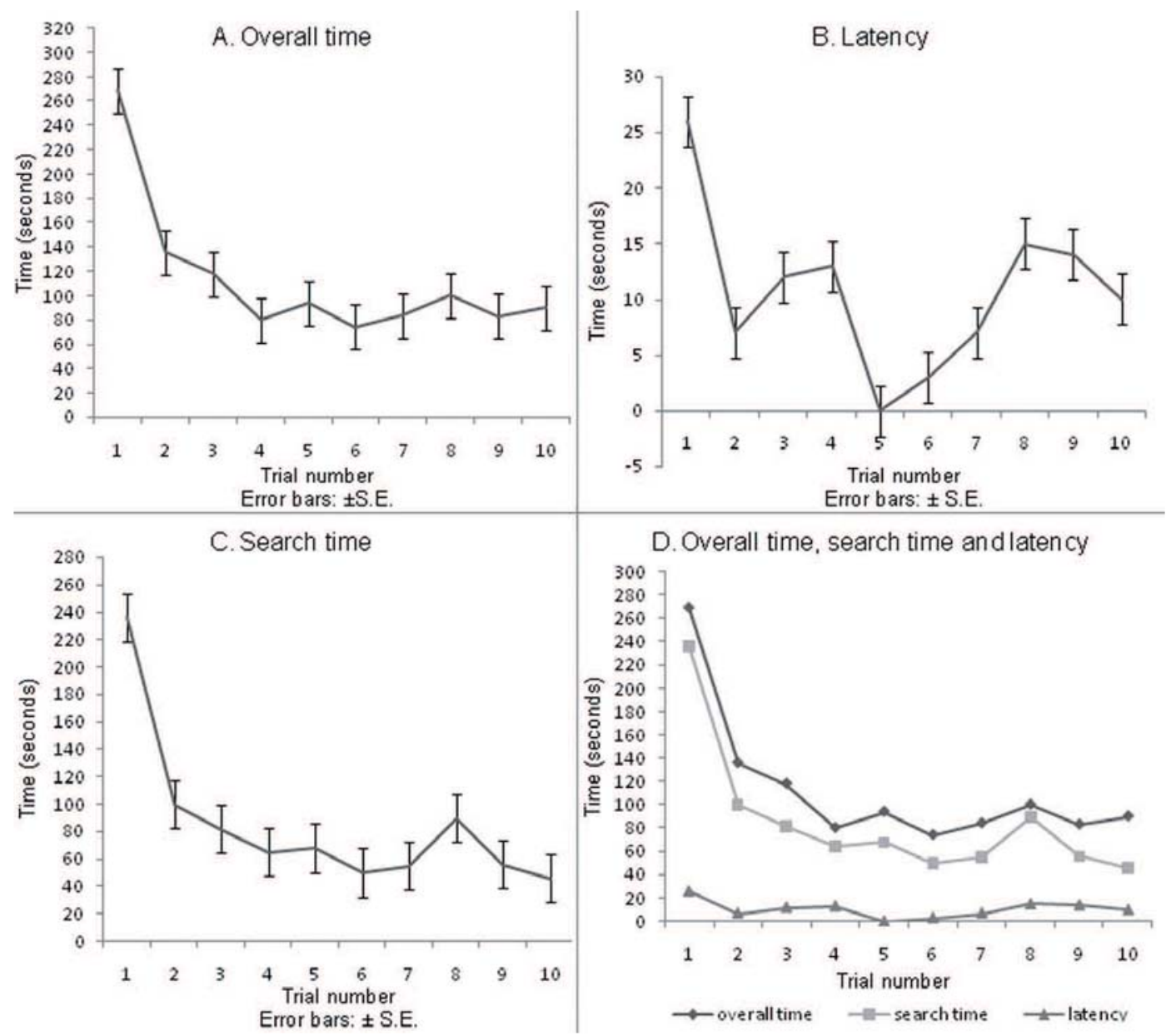

Figure 2: Variation of the time spent inside the box across the 10 trials. As error bars representing standard errors suggest, wide variation between individuals in the overall time, latency and search time was observed. (a) Overall time, between the moment of release and the moment of escape. (b) Time passed until the individual's first action. Detraction was not considered a "first movement". (c) Time spent actively exploring the enclosure, after the first movement and until escape. (d) All before-mentioned variables plotted together for comparison purposes.

(Fig. 3a) (rs=0.951, $P<0.001)$. Analysis of the relationship between the overall time and latency also returns a positive correlation, but not as strong as the one between overall search time and active search time ( $r s=0.697$, $P=0.029$; Fig. $3 b$ ). No statistically significant relationship was found between latency and active search time (rs=0.55, $P=0.099$; Fig. $3 \mathrm{c}$ ).
Performance (measured by variation in the search time) was not influenced by the activity at the moment of encounter at any stage of the test. Individuals involved in a high level of activity (median search time: $276 \pm 282 \mathrm{~s}, \mathrm{~N}=19$ ) did not perform better than those less active (median search time: $206.5 \pm 126 s, \mathrm{~N}=12$ ) during the first trial 

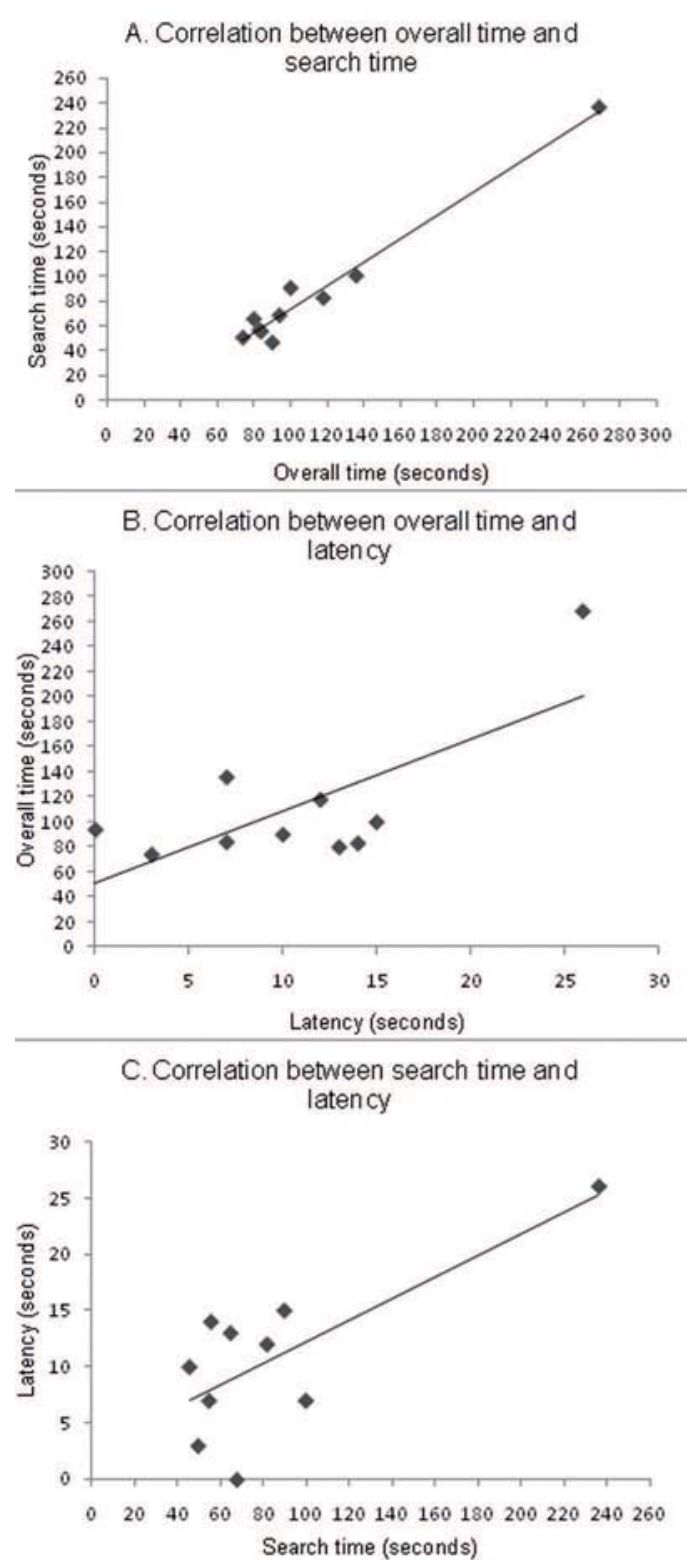

Figure 3: Correlations between variables collected during trials. (a) Graph showing strong positive correlation between the overall time needed to complete the trials and the time spent actively exploring the box. (b) Graph showing weak positive correlation between overall time needed to complete the trials and latency to the first movement. (c) Graph showing independent variation of the active search time and latency to the first movement.
(W $=118, P=0.889)$ and this was maintained for the fifth trial (W $=131.5, P=0.490$; high level of activity: median $=88 \pm 127 \mathrm{~s}$, $\mathrm{N}=19$; low level of activity: median $=49.5 \pm$ $80 \mathrm{~s}, \mathrm{~N}=12$ ) and for the tenth trial (W = 135.5, $P=0.394$; high level of activity: median $=81 \pm$ $77 \mathrm{~s}, \mathrm{~N}=19$; low level of activity: median $=41.5$ $\pm 82 \mathrm{~s}, \mathrm{~N}=12$ ).

Only 11 of the 31 subjects showed consistency in the path followed after being reintroduced in the box, i.e. the first successful movement was repeated for at least eight trials. One of these subjects was a female and the rest were males.

The air temperature did not seem to influence whether the subjects completed or failed the trials, as successful individuals did not perform the test at a significantly different temperature than unsuccessful ones (W $=203$, $P=0.359$; successful individuals: median temperature $=30.1^{\circ} \mathrm{C}, \mathrm{N}=31$; unsuccessful individuals: median temperature $=30.1^{\circ} \mathrm{C}, \mathrm{N}=11$ ).

\section{DisCUSSION}

This study demonstrates that Greek tortoises are capable of finding and operating the correct door in order to escape from the experimental set-up used. For all but two subjects, the time needed to complete the tenth trial was less than the time needed to complete the first trial, which is the first indication of the development of a strategy of some sort. Although the overall time needed to complete the trials decreases in a fashion that readily suggests the acquisition and learning of a certain escape mechanism, the active search time is a better indicator of an improvement in performance variation. Latency remained relatively constant throug- 
hout the tests (Figs. 2b and 2d) owing to the fact that the subjects were reluctant to perform any movements soon after being placed (back) into the box. Therefore, latency represents an increasingly higher proportion of the overall time as the active search time decreases. The active search time shows a more realistic variation of the tortoises' performance and thus gives a more reliable measurement. The fact that tortoises spent significantly less time exploring the box as the tests progressed clearly suggests that they have learned and used a strategy. At some point during the test, each individual stood immobile in front of each wall, looking directly forwards, suggesting that they were scanning the surroundings. The square shape of the enclosure prevented orientation according to large scale geometry, as reported for a wide variety of species (see above), thus the local cues (i.e. the geometrical shapes attached to the walls) are likely to have been used.

As illustrated in Figs. 2c and 2d, there is a slight increase in the search time during the last trial compared to the previous five trials, and the same trend reflects on the overall time (Figs. 2a and 2d). It is suggested for other reptile species that when an increase in familiarity of the environment is accompanied by a decrease in activity, this could be attributed to the fact that the subjects become comfortable within the enclosure (HoltzMAN et al., 1999; Chiszar et al., 1976, cited in HolTZMAN et al., 1999). It is very unlikely that this is the case here. Certain individuals showed clear signs of stress, such as urinating, defecating, fighting vigorously when handled and retracting when being placed back inside the box after the completion of a trial, which is expected from wild, expe- rimentally naïve animals. This slight increase during the last part of the test is probably due to exhaustion, as most of the individuals moved around the box constantly, climbing and scratching the walls.

The use of extra-maze cues during orientation tasks is reported for other species, including chelonians (LÓPEZ et al., 2000, 2001, 2003; WILKINSON et al., 2009). In the present study, as it was impossible to completely isolate the box from the surroundings, elements of the environment, such as tree branches and tall plants, were visible from within. A common behaviour was climbing the walls, usually at the corners, leaning against with the front limbs, looking outside and trying to escalate. Thus, the hypothesis that tortoises used the environmental cues as a guidance strategy cannot be ruled out.

The activity at the moment of encounter was expected to reflect on the subjects' behaviour inside the box. Individuals involved in a less energy demanding activity (resting, basking, feeding) were expected to require a longer time to complete the trials, while more active individuals (walking) were expected to complete the trials faster since they were already involved in a navigation process. This hypothesis was not supported, suggesting that the ability to use geometrical shapes to navigate is part of a set of cognitive processes that can be employed whenever the circumstances require it.

The fact that less than half of the successful individuals met the significance criterion of $80 \%$ first movements identical to the first successful one suggests that repeated transfers back into the box are disorienting and the subjects cannot maintain a constant path, requiring a certain amount of time to compute the spatial arrangement of the arena. 
There is evidence of different learning abilities and spatial use between sexes, which is possibly accentuated during breeding season (JACOBS, 1996). Male Greek tortoises do not use colours, vocalisations or any other advertisements to attract mates but have to actively search for them and consequently are expected to perform better in spatial tasks than females. A biased sex ratio towards males (24 out of the 31 subjects), while not necessarily unusual (see MEEK, 1985 for a Hermann's tortoise population survey), did not allow this assumption to be tested.

Tests for the importance of olfaction in reptile spatial tasks have provided mixed results (GRAHAM et al., 1996; WILKINSON et al., 2013). Gular pumping, which is linked to the use of olfaction (GRAHAM et al., 1996) was observed in a few cases. The paint used for the geometrical shapes had a characteristic smell, however this was uniformly spread. Although the procedure was designed to minimize odour trails between individuals, no measures were taken to eliminate any odour traces between the trials of the same test, so the possibility that the tortoises oriented according to their own odour traces cannot be ignored.

It has been reported for desert tortoises, Gopherus agassizii, that at temperatures higher than $29^{\circ} \mathrm{C}$ a change in behaviour towards seeking cover occurs (Hinderle, 2011). Exposure to environmental temperatures higher that $40^{\circ} \mathrm{C}$ for more than one hour are unsafe for Greek tortoises, and body temperatures higher than $38^{\circ} \mathrm{C}$ for prolonged periods hasten dehydration (LAGARDE et al., 2012). In this particular study, temperature did not influence the outcome of the test (failed/completed), but a more detailed impact on the subjects' performance is not readily obvious.
Due to its nature, the present study has a series of inevitable limitations, as with all behavioural studies conducted on wild animals. Although it can be approximated with sufficient confidence whether the tortoises were adults or juveniles, the exact age was not known. Also, nothing was known about the life histories of the individuals or their health conditions. It has been shown for other species that certain diseases, in the infective phase, impair learning abilities (JACOBS, 1996). There is a high chance that the majority of tortoises in this study have never encountered humans before. The carapaces and plastrons of some specimens showed signs of accidents that may have left traumas.

The low degree of comfort around humans is also reflected by the fact that all individuals ignored the food reward, as their only interest once outside was to move as far away as possible. The heterogeneity of the sample is best reflected by the number of individuals that failed the test completely (26\% of the entire sample), firstly, and secondly by the widely variable behaviour of the successful individuals, from different points of view. Many different levels of performances were observed, as seen in Fig. 2. The lack of training prior to the tests is most likely responsible for the fact that seven individuals needed between one and three extra trials before being able to find the exit by themselves.

Unlike other animals tested for geometrical shape determination, such as the fiddler crabs (LANGDON \& HERRNKIND, 1985) or hermit crabs (DiAZ et al., 1995) which were assigned ecologically-relevant tasks, the Greek tortoises in the present experiment were tested in an artificial environment. They are not faced with similar tasks in their natural habitat, but the trials provide insights into their cognitive processes, including learning and memory. 
This study supports the idea that reptiles are capable of performing similarly to mammals and birds in spatial tasks. From a spatial orientation point of view, chelonians are unique among reptiles in that they tend to navigate more similarly to birds and mammals than other reptilian groups (Wilkinson \& HubER, 2012). Since their position within the reptile group is uncertain (mitochondrial DNA analysis suggests chelonians are closely related to birds and crocodiles while morphological features point towards a closer relatedness to lizards and snakes (Zardoya \& MeYer, 2001; WiLKINSON \& HUBER, 2012), studies of cognitive abilities might provide further insights into the group's evolutionary history.

Our experiment supports the hypothesis that Greek tortoises are able to discriminate between simple geometrical shapes. Further studies should focus on the importance of this ability for navigation in the species' natural environment.

\section{Acknowledgement}

The study was approved by the University of Derby bioethics committee and all data collection procedures complied with animal welfare legislation. The authors thank the academic and technical staff of the School of Biological Sciences at the University of Derby and field assistants, A. and C. Pandrea for volunteering to help with data collection.

\section{REFERENCES}

ABLe, K.P. (1991). Common themes and variation in animal orientation systems. American Zoologist 31:157-167.

Carretero, M.A.; Znari, M.; Harris, D.J. \& MACÉ, J.C. (2005). Morphological divergence among population of Testudo graeca from west-central Morocco. Animal Biology 55:259-279.

Cheng, K. (1986) A purely geometric module in the rat's spatial representation. Cognition 23:149-178.

Cheng, K. \& Gallistel, C.R. (1984). Testing the geometric power of an animal's spatial representation, In H.L. Roitblat, T.G. Bever \& H.S. Terrace (eds.) Animal Cognition. Erlbaum Associates, Hillsdale, NJ, USA, pp. 409-423.

ChIUSSI, R. \& DiAZ, H. (2002). Orientation of the fiddler crab, Uca cumulanta: responses to chemical and visual cues. Journal of Chemical Ecology 28:1787-1796.

Covaciu-Marcov, S.-D.; GHIRA, I.; CicorTLuCaciu, A.-Ş.; SAS, I.; Strugariu, A. \& Bogdan, H.V. (2006). Contributions to knowledge regarding the geographical distribution of the herpetofauna of Dobrudja, Romania. North-Western Journal of Zoology 2:88-125.

Deipolyi, A.; Santos, L. \& Hauser, M.D. (2001). The role of landmarks in cottontop tamarin spatial foraging: evidence for geometric and non-geometric features. Animal Cognition 4:99-108.

DiaZ, H.; ForWARD, R.B., Jr.; OrinUela, B. \& RitTschof, D. (1994). Chemically stimulated visual orientation and shape discrimination by the hermit crab Clibanarius vittatus (Bosc). Journal of Crustacean Biology 14:20-26.

Diaz, H.; Orihuela, B. \& Forward, R.B., JR. (1995). Visual orientation of postlarval and juvenile mangrove crabs. Journal of Crustacean Biology 15:671-678.

El Mouden, E.H.; Slimani, T.; Ben Kaddour, K.; Lagarde, F.; OUhammou, 
A. \& Bonnet, X. (2006). Testudo graeca graeca feeding ecology in an arid and overgrazed zone in Morocco. Journal of Arid Environments 64:422-435.

Gallistel, C.R. (1990). The Organization of Learning. The MIT Press, Cambridge, MA, USA.

Gouteux, S.; Thinus-Blanc, C. \& VAuClair, J. (2001). Rhesus monkeys use geometric and nongeometric information during a reorientation task. Journal of Experimental Psychology: General 130:505-519.

Graham, T.; Georges, A. \& McElhinney, N. (1996). Terrestrial orientation by the Eastern Long-necked Turtle, Chelodina longicollis, from Australia. Journal of Herpetology 30:467-477.

Hermer, L. \& SpelKe, E. (1996). Modularity and development: the case of spatial reorientation. Cognition 61:195-232.

Hinderle, D. (2011). Desert Tortoises (Gopherus agassizii) and Translocation: Homing, Behavior, Habitat and Shell Temperature Experiments. M.Sc. Thesis, San Diego State University, San Diego, CA, USA.

Holtzman, D.A.; Harris, T.W.;

Aranguren, G. \& Bostock, E. (1999).

Spatial learning of an escape task by young corn snakes, Elaphe guttata guttata. Animal Behaviour 57:51-60.

JACOBS, L.F. (1996). Sexual selection and the brain.

Trends in Ecology and Evolution 11:82-86.

Lagarde, F; LouZizI, T.; Slimani, T.; El Mouden, H.; Ben Kaddour, K.; Moulherat, S. \& Bonnet, X. (2012). Bushes protect tortoises from lethal overheating in arid areas of Morocco. Environmental Conservation 39:172-182.

LAMberT, M.R.K. (1982). Studies on the growth, structure and abundance of the
Mediterranean spur-thighed tortoise, Testudo graeca in field populations. Journal of Zoology 196:165-189.

LANGDON J.W. \& HERRNKIND, W.F. (1985).

Visual shape discrimination in the fiddler crab, Uca pugilator. Marine Behavior and Physiology 11:315-325.

López, J.C.; Rodríguez, F.; Gómez, Y.; Vargas, J.P.; Broglio, C. \& Salas, C. (2000). Place and cue learning in turtles. Animal Learning and Behavior 28:360-372. LÓPEZ, J.C.; GÓMEZ, Y.; Rodríguez, F.; Broglio, C.; Vargas, J.P. \& Salas, C. (2001). Spatial learning in turtles. Animal Cognition 4:49-59.

LÓPEZ, J.C.; VARGAS, J.P.; GÓMEZ, Y. \& SALAS, C. (2003). Spatial and non-spatial learning in turtles: the role of medial cortex. Behavioural Brain Research 143:109-120.

MÄTHGER, L.M.; LITHERLAND, L. \& FRITSCHES, K.A. (2007). An anatomical study of the visual capabilities of the green turtle, Chelonia mydas. Copeia 2007: 169-179.

MeEK, R. (1985). Aspects of the ecology of Testudo hermanni in southern Yugoslavia. British Journal of Herpetology 6:437-445.

Narazaki, T.; Sato, K.; Abernathy, K.J.; Marshall, G.J. \& MiYaZAKi, N. (2013). Loggerhead turtles (Caretta caretta) use vision to forage on gelatinous prey in mid-water. PLoS ONE 8: e66043.

Orihuela, B.; Díaz, H.; Forward, R.B., JR. \& RitTsCHOF, D. (1992). Orientation of the hermit crab Clibanarius vittatus (Bosc) to visual cues: effects of mollusc chemical cues. Journal of Experimental Marine Biology and Ecology 164:193-208. R Development Core TeAm (2008). $R$ : $A$ Language and Environment for Statistical Computing: An Online Reference. R 
Foundation for Statistical Computing, Vienna, Austria. Available at: http://www.rproject.org/. Retrieved on 07/17/2013.

Rodríguez, F.; López, J.C.; Vargas, J.P.;

Gómez, Y.; Broglio, C. \& Salas, C. (2002). Conservation of spatial memory function in the pallial forebrain of reptiles and ray-finned fishes. Journal of Neuroscience 22:2894-2903.

Schluessel, V.; Fricke, G. \&BleckmanN, H. (2012). Visual discrimination and object categorization in the cichlid Pseudotropheus sp. Animal Cognition 15:525-534.

Sereau, M.; Lagarde, F.; Bonnet, X.; El Mouden, E.H.; Slimani, T.; Dubroca, L.; Trouvé, C.; Dano, S. \& Lacroix, A. (2010). Does testosterone influence activity budget in the male Greek tortoise (Testudo graeca graeca)? General and Comparative Endocrinology 167:181-189.

SiebeCK, U.E.; Litherland, L. \& Wallis, G.M. (2009). Shape learning and discrimination in reef fish. Journal of Experimental Biology 212:2113-2119.

SOVRANO, V.A.; BisAZZA, A. \& VAlLORTIGARA, G. (2002). Modularity and spatial reorientation in a simple mind: encoding of geometric and nongeometric properties of a spatial environment by fish. Cognition 85: B51-B59.

SOVRANO, V.A.; BISAZZA, A., \& VAllortigara, G. (2003). Modularity as a fish (Xenotoca eiseni) views it: conjoining geometric and nongeometric information for spatial reorientation. Journal of Experimental Psychology: Animal Behavior Processes 29:199-210.

SuBoski, M.D. (1992). Releaser-induced recognition learning by amphibians and reptiles. Animal Learning and Behavior 20:63-82.
Tortoise and Freshwater Turtle Specialist Group (1996). Testudo graeca. The IUCN Red List of Threatened Species, Gland, Switzerland. Available at: http://www.iucnredlist.org/details/full/21 646/0. Retrieved on 07/17/2013.

Wilkinson, A. \& HuBER, L. (2012) Cold-blooded cognition: reptile cognitive abilities, In T.K. Shackelford \& J. Vonk (eds.) The Oxford Handbook of Comparative Evolutionary Psychology, Oxford University Press, Oxford, UK, pp. 129-144.

Wilkinson, A.; Chan, H.-M. \& Hall, G. (2007). Spatial learning and memory in the tortoise (Geochelone carbonaria). Journal of Comparative Psychology 121:412-418.

Wilkinson, A.; Coward, S. \&Hall, G. (2009). Visual and response-based navigation in the tortoise (Geochelone carbonaria). Animal Cognition 12:779-787.

Wilkinson, A.; Kuenstner, K.; Mueller, J. \& Huber, L. (2010). Social learning in a non-social reptile (Geochelone carbonaria). Biology Letters 6:614-616.

Wilkinson, A.; Mueller-Paul, J. \& Huber, L. (2013). Picture-object recognition in the tortoise Chelonoidis carbonaria. Animal Cognition 16:99-107.

Wystrach, A. \& Beugnon, G. (2009). Ants learn geometry and features. Current Biology 19:61-66.

Zardoya, R. \& Meyer, A. (2001). The evolutionary position of turtles revised. Naturwissenschaften 88:193-200.

Znari, M.; Germano, D.J. \& Macé, J.-C. (2005). Growth and population structure of the Moorish Tortoise (Testudo graeca graeca) in Westcentral Morocco: possible effects of over-collecting for the tourist trade. Journal of Arid Environments 62:55-74. 